\title{
Creation and validation of an instrument to identify nursing activities in pediatric wards: information for determining workload
}

\author{
CONSTRUÇÃO E VALIDAÇÃO DE INSTRUMENTO PARA IDENTIFICAÇÃO DAS \\ ATIVIDADES DE ENFERMAGEM EM UNIDADES PEDIÁTRICAS: SUBSÍDIO PARA \\ DETERMINAÇÃO DA CARGA DE TRABALHO \\ CONSTRUCCIÓN Y VALIDACIÓN DE UN INSTRUMENTO PARA IDENTIFICAR LAS \\ ACTIVIDADES DE ENFERMERÍA EN LAS UNIDADES PEDIÁTRICAS: UN APOYO PARA \\ LA DETERMINACIÓN DE LA CARGA DE TRABAJO
}

Nanci Cristiano Santos ${ }^{1}$, Fernanda Maria Togeiro Fugulin ${ }^{2}$

\begin{abstract}
The aim of this study was to develop and validate an instrument for identifying nursing activities performed in a pediatric ward and to provide a basis for defining the workload of these units. The instrument was developed by selecting the activities relevant to pediatric nursing from the Nursing Intervention Classification and then submitting them to a panel of judges for validation. The panel considered the selected activities relevant and representative of pediatric nursing practice. Now that representative activities for the nursing workload have been identified, we envision new studies to verify their usefulness in practice. Determining the amount of time each activity takes to perform will help to develop a system for measuring the workloads of nursing teams in pediatric wards.
\end{abstract}

\section{DESCRIPTORS}

Pediatric nursing

Workload

Personnel administration, hospital

Validation studie

\section{RESUMO}

A pesquisa teve por objetivo construir e validar um instrumento para identificação das atividades de enfermagem realizadas em unidades pediátricas, como subsídio para definição da carga de trabalho dessas unidades. $O$ instrumento foi elaborado com base na Classificação das Intervenções de Enfermagem, selecionando-se as atividades consideradas relevantes para a assistência de enfermagem pediátrica e, posteriormente, submetido a um grupo de juízas, que realizaram sua validação, que considerou as atividades selecionadas relevantes e representativas da prática de enfermagem pediátrica. Com a identificação das atividades, que representam a carga de trabalho de enfermagem, vislumbra-se o desenvolvimento de novas pesquisas para verificar sua aplicabilidade na prática. A correlação de cada uma delas com o tempo despendido para sua realização constituirá um instrumento para determinar a carga de trabalho da equipe de enfermagem em unidades pediátricas.

\author{
DESCRITORES \\ Enfermagem pediátrica \\ Carga de trabalho \\ Administração de recursos humanos em \\ hospitais \\ Estudos de validação.
}

\begin{abstract}
RESUMEN
La investigación tuvo como objetivo construir y validar un instrumento para la identificación de las actividades de enfermería realizadas en unidades pediátricas, como un auxilio para la definición de la carga de trabajo en dichas unidades. El instrumento fue elaborado basado en la Clasificación de las Intervenciones de Enfermería, seleccionándose las actividades que fueron consideradas relevantes en la atención de enfermería pediátrica, y posteriormente, sometido a un grupo de jueces, que realizó su validación, quienes consideraron las actividades seleccionadas relevantes y representativas de la práctica de enfermería pediátrica. Con la identificación de las actividades que representan la carga de trabajo de enfermería, se prevé el desarrollo de nuevas investigaciones para verificar su aplicación en la práctica. La correlación de cada una de ellas con el tiempo empleado para su realización, constituirá un instrumento para determinar la carga de trabajo del equipo de enfermería de las unidades pediátricas.
\end{abstract}

\section{DESCRIPTORES}

Enfermería pediátrica

Carga de trabajo

Administración de personal en hospitales Estudios de validación

${ }^{1}$ Nurse practitioner. Masters in Nursing. Nurse at the University of São Paulo Hospital. São Paulo, SP, Brazil. nanci.cristiano@hu.usp.br ${ }^{2}$ Nurse practitioner. Associate Professor. Associate Professor of the Department of Professional Counseling at the School of Nursing of the University of São Paulo. São Paulo, SP, Brazil. ffugulim@usp.br 


\section{INTRODUCTION}

Planning and performing qualitative and quantitative analyses concerning nursing personnel are important managerial tasksin nursing that require specific methods and instruments.

In Brazil, one method ${ }^{(1)}$ for determining staff size is based on the activities performed. Systematizing nursing can facilitate predictions about necessary nursing staff in a health institution. One of the main steps in this method ${ }^{(1)}$ is identifying the workload of the nursing unit, which is the sum of the product of the average daily number of patients/clients treatedy the average time required for each patient based on the their degree of dependence on the nursing team ${ }^{(2)}$.

To identify this variable, one must adopt a patient classification system (PCS) to understand the degree of dependence of the patients on the nursing team and the average amount of time needed to meet their needs.

Including a PCS in nursing management helps to improve the models used to determine the nursing team's workload because it shows the variability of the average time dedicated to patients receiving various types of care $^{(3)}$.

Studies on nurse staffing use PCSs as the basis for measuring patient care time to establish the relationship between each category of care and the average patient care times in the literature.

Because official parameters for operationalizing the nurse staffing process do not exist, the Brazilian Federal Nursing Council (Conselho Federal de Enfermagem - COFEN) established Resolution No. 293/04(4) to offer minimum parameters for staff sizes in Brazilian hospitals, including the percentage distribution of the employees and the average hours needed for each type of care based on the $\mathrm{PCS}^{(5)}$ developed in a teaching hospital in the city of São Paulo.

However, a study conducted using this system showed that it did not apply to patients in nursery and pediatric wards; in addition, it does not identify the different levels of dependence on nursing for patients in the intensive care unit (ICU) ${ }^{(3)}$. The authors of the study proposed the development of specific instruments for neonatology and pediatrics and suggested that specific instruments for critical care units that more accurately reflect the reality and the characteristics of critical care patients should be developed, tested and validated ${ }^{(3)}$.

Internationally, instruments have been proposed to measure nursing workloads in adult ICUs by identifying the care needs of the patients and the time spent caring for them, thus allowing hospitals to plan and assess the qualitative and quantitative suitability of the personnel for this type of unit ${ }^{(6-7)}$.

However, although instruments have been developed $^{(8-9)}$ in the areas of pediatrics and neonatology to evaluate the severity of the patients, instruments that measure nursing workloads are scarce. None of the studies account for the types of nursing care activities performed and the time spent on them.

The lack of a benchmark for classifying pediatric and neonatal patients based on their specific characteristics leads nurses to classify the patients erroneously, using parameters that do not relate to their real needs and ultimately leading to inaccurate planning for nurse staffing.

Recently, a classification system for Brazilian pediatric patients was proposed ${ }^{(10)}$. However, this system ${ }^{(10)}$ does not translate the nurse staffing requirement into hours of care, and thus, the relationship between categories of care and the average times spent caring for patients must be established based on the literature, which usually refers to adults. Even COFEN ${ }^{(4)}$ did not contemplate the specific needs of pediatric patients when it endorsed the categories of care based on the characteristics and profiles of adult patients.

In practice, there are gaps in the proposal and the validity of the time spent caring for the needs of patients admitted to the pediatric ward, and studies that use objective methods for identifying the nursing team's workload in these wards are lacking.

Current studies on nurse staffing have shown that the type and frequency of the interventions performed by the nursing staff more accurately predict the team's workload. The method used seeks to identify the required interventions and the average amount of time used to perform them.

In the United States, the fifth edition of the Nursing Intervention Classification (NIC) ${ }^{(11)}$ describes the interventions that nurses perform in nursing practice and indicates the estimated time required for each. The proposed values were based on the judgment of professionals familiar with the intervention and the area of care, and thus, they may differ by institution and care provider ${ }^{(11)}$.

The NIC uses standardized language to describe the interventions and the activities that the nurses perform in nursing practice in response to an established nursing diagnosis ${ }^{(11)}$. A nursing intervention is defined as any treatment, based upon clinical judgment and knowledge that a nurse performs to enhance patient outcomes and the activities related to specific behaviors or actions to implement an intervention ${ }^{(11)}$.

In Brazil, several studies have used the NIC to identify the nursing interventions/activities performed in practice. These studies have formed a foundation for 
identifying the amount of time spent caring for patients in wards that do not have PCSs or wards in which PCSs are inappropriate, including the newborn ward ${ }^{(12)}$, urgent care $^{(13)}$, primary health care ${ }^{(14)}$ and surgical centers ${ }^{(15)}$.

These studies ${ }^{(12-15)}$ concluded that the NIC is an important theoretical/practical reference that makes it possible to identify the nursing interventions/activities performed in various scenarios and offers a foundation for measuring the amount of time spent (and consequently, determining the workload of the nurses).

Therefore, we believe that an instrument for measuring the workload of nursing teams in pediatric wards (i.e., the time spent caring for the specific needs of these clients) may serve as a management tool that can support the process used to determine nurse staffing in this area, helping to address the problems in planning and acquiring nursing staff in pediatrics.

Thus, the aim of this study was to create and validate an instrument to identify the nursing activities performed in pediatric wards, thereby creating a basis for future studies to measure the time spent performing these activities and subsequently to create an instrument for measuring the nursing workload in pediatric wards.

\section{METHOD}

This is a methodological development study ${ }^{(16)}$ conducted in two phases: the development of an instrument for identifying nursing activities performed in pediatric wards and the validation of the instrument developed.

The instrument was developed with the NIC as a theoretical reference because it uses a standardized language for nursing. Thus, the instrument will have a common meaning for diverse care settings, helping to improve nursing practice and management with studies designed to enable the comparison and evaluation of nursing care conducted in various scenarios ${ }^{(11)}$.

The taxonomic structure of the NIC contains three levels, the first of which includes seven domains: physiological, basic; physiological, complex; behavioral; safety; family; health system; and community. The second level has 30 classes organized into domains, and the third level has 542 interventions grouped into classes and domains. The domains are designated 1 to 7 , and the classes are designated $A$ to $Z$ and $a, b, c$ and d. Each intervention has a single four-digit code and contains a list of ten to 30 activities $^{(11)}$.

Each nursing intervention contains a title, definition and a list of activities. The title and the definition, which are written in standardized language, should not be changed except after a formal revision process. However, the activities can change, as long as they remain consistent with the definition of the intervention ${ }^{(11)}$.
The development of the instrument began with several readings of the $\mathrm{NIC}^{(11)}$ to understand its complex structure, to review the definitions of each domain, class and intervention and to identify the relevant activities listed under each intervention. The activities were then edited by the researchers based on their clinical experience in the area to select the activities that are essential for pediatric nursing practice (i.e., those most often performed by the nursing team).

The selected activities were maintained within the domains and classes, preserving the hierarchical grouping established in the NIC as well as the nomenclature, the definitions and the identification codes. Next, the activities were sorted from smallest to largest according to the estimated time needed to complete the task. Each level was assigned a code and a rank number.

In the second phase of the study, the instrument was validated by assessing the face validity, a type of content validity. Face validity is considered an intuitive type of validation in which colleagues or research subjects are asked to evaluate the content of an instrument to determine whether the instrument reflects what the researcher wants to measure ${ }^{(16)}$.

In this study, the face validity assessment served to verify whether the selected and described activities were representative of pediatric nursing care practice and whether the instrument would be appropriate for measuring the workload of nursing teams in this field.

When assembling the group of specialists who validated the instrument, we considered it necessary to include at least one nurse with knowledge in each of the areas involved in its development: pediatric nursing care, workloads and the NIC.

Thus, nurses with at least five years of experience practicing or teaching pediatric nursing and teaching or conducting studies on the other themes were included. The specialist panel consisted of four nurses with considerable professional experience and specialty knowledge of pediatrics, workloads and the NIC.

The group of specialists was tasked with analyzing the content of the instrument for clarity, the appropriateness of the activity classifications into domains and classes, the clarity of the activity descriptions, the order of the activities according to complexity, the relevance of the activities to pediatric nursing care, the inclusion or exclusion of classes in the domains, and whether the proposed instrument reflected pediatric nursing care practice. This analysis was accomplished using a questionnaire with close-ended dichotomous questions, with space for comments if applicable.

An invitation was sent to the specialists explaining the aims of the study and containing the written informed consent form, the introduction to the questionnaire and instructions for filling out the questionnaire
Creation and validation of an instrument to identify nursing activities in pediatric wards: information for determining workload Santos NC, Fugulin FMT 
and the questionnaire itself. The documents were sent by e-mail, and the reviewers were given 20 days to return the questionnaire.

The specialists' responses were examined to find areas where they agreed and disagreed, items they liked and suggestions for the items. The specialists' evaluations were used to make changes, resulting in a second version that was re-sent to the group for re-evaluation along with an invitation to a workshop to discuss and build consensus on the content of the new instrument.

The workshop, scheduled at the specialists' convenience, included all of the invitees and began with a summary of the changes made to the instrument based on the previous evaluation. Next, each item on the instrument was discussed and analyzed until there was consensus about the activities included in each class, the distinct nature of the activities at increasing levels and the differences in the workload associated with activities at different levels. The group continued to the next item only after consensus was reached for all of the aspects of an item.

The research project and the informed consent form were approved by the Research Ethics Committee at the University of São Paulo Hospital (protocol no. 614/05).

\section{RESULTS}

The initial instrument included five domains represented by numbers and 20 classes represented by letters. The chosen classes were included in the instrument under their corresponding domains, and all included the definition found in the NIC. The selected activities in each class were described in three to six incremental levels based on the estimated time needed to perform them.

During the first evaluation phase, the responses, comments and suggestions from the specialists were analyzed to determine whether there was agreement about the activities that were included in each domain and each class. The inclusion or exclusion of domains and classes in the instrument was not suggested.

The specialists identified activities that were not described clearly and objectively and activities that were not listed in increasing order based on the estimated time needed to perform the task. All of the participants thought that the described activities were relevant and representative of pediatric nursing care. They also made suggestions about changing the title of the instrument, standardizing the writing style, excluding items that were done by the patient independent of the nursing team, excluding the choice about whether the activity would be done by the nursing team for activities that are always done by nurses and excluding the role of the employee performing the activity to avoid restricting who performs the activity and maintaining the same number of items in all of the classes.

The suggestions and comments of the specialists determined the changes made to the classification system, and a new proposal was reevaluated by the group at the workshop, which lasted three hours. The changes to the instrument made at the workshop included the substitution of some terms used for various items in the instrument to better describe the activity; the separation of activities that are distinct or have different workloads into different items; the removal of the activity transport from Class $C$ because it was also part of the patient referral in Class $a$; and the addition of the activity hold child on lap in Class R to show the need to calm the child, an important activity in pediatric units.

The final instrument, which was developed based on the consensus of the specialist group, contained five domains and 20 classes, but the number of levels in each class ranged from three to ten, as shown in Charts 1,2 , 3,4 and 5 .

Chart 1 - Validated nursing activities in Domain 1 - Physiological, Basic - São Paulo, SP, 2010.

\begin{tabular}{|ll|}
\hline Domain 1: PHYSIOLOGICAL, BASIC - Care given to support physical functioning ${ }^{(11)}$ \\
\hline Class A:Activity and Exercise Management-Interventions to organize or support physical activity and energy expenditure and conservation ${ }^{(11)}$. \\
\hline A1 & Control physical activity. \\
A2 & Provide movement/ambulation support (one nurse). \\
A3 & Provide movement/ambulation support (two or more nurses). \\
\hline Class B: Elimination Management- Interventions to establish and maintain regular bowel and urinary elimination patterns and to manage \\
complications due to altered patterns(11). \\
\hline B1 & Conduct long-term indwelling catheterization during a shift. \\
B2 & Change diapers/perform perineal hygiene in patients with normal frequency of eliminations. \\
B3 & Provide assistance in using the toilet/bedpan/urinal for patients with normal frequency of eliminations. \\
B4 & Control the volume of the eliminations. \\
B5 & Perform intermittent catheterization up to four times in a 24-hour period. \\
B6 & Change diapers/perform perineal hygiene in patients with increased elimination frequency. \\
B7 & Provide assistance using the toilet/bedpan/urinal for patients with increased frequency of eliminations. \\
\hline
\end{tabular}


Class C: Immobility Management -Interventions to manage restricted body movement and the sequelae ${ }^{(11)}$.

C1 Perform care on positioning/traction/casting (one nurse).

C2 Assist with a position change/bed transfer (one nurse).

C3 Assist with/perform active and passive range of motion exercises (one nurse).

C4 Perform a position change/bed transfer (two or more nurses).

C5 Assist with/perform care activities on positioning/traction/casting (two or more nurses).

Class D: Nutrition Support-Interventions to modify or maintain nutritional status ${ }^{(11)}$.

D1 Control uptake and tolerance of food/water.

D2 Control daily weight.

D3 Assist or administer food/liquids orally (including bottles and sippy cups).

D4 Control weight two or more times in a 24-hour span.

D5 Administer food/liquid through tubes.

D6 Administer food/liquid orally to patients with abnormal sucking and/or swallowing.

D7 Provide parenteral nutrition.

Class E: Physical Comfort Promotion -Interventions to promote comfort using physical techniques ${ }^{(11)}$.

E1 Monitor nausea and vomiting.

E2 Monitor and use scales for measuring pain.

E3 Implement measures for controlling and alleviating nausea, vomiting and pain.

E4 Promote sleep and rest.

Class F: Self-Care Facilitation -Interventions to perform or assist with activities of daily living ${ }^{(11)}$.

F1 Assist with/perform oral hygiene.

F2 Assist with/perform intimate hygiene.

F3 Assist with or change clothes.

F4 Assist with/perform bath in a shower, bath or chair (one nurse).

F5 Provide a bath in the incubator.

F6 Assist with/perform a bath in a shower, bath or chair (two or more nurses).

F7 Perform a sponge bath in bed (one nurse).

F8 Perform a sponge bath in bed (two or more nurses).

Chart 2 - Validated nursing activities in Domain 2 - Physiological,Complex - São Paulo, SP, 2010

Domain 2: PHYSIOLOGICAL, COMPLEX - Care activities that support homeostatic regulation ${ }^{(11)}$.

Class G: Electrolyte and Acid-Base Management-Interventions to regulate electrolyte/acid-base balance and prevent complications ${ }^{(11)}$.

G1 Manage glycosuria/ketonuria.

G2 Manage capillary blood glucose.

G3 Manage electrolyte and blood gas levels.

G4 Administer oral rehydration therapy.

G5 Perform dialysis procedures.

Class H: Drug Management -Interventions to facilitate desired effects of pharmacological agents ${ }^{(11)}$.

H1 Administer drugs through tubes.

H2 Administer drugs orally.

H3 Administer drugs by inhalation.

H4 Administer drugs by IM/ID/SC routes.

H5 Administer drugs through continuous IV.

H6 Administer drugs by intermittent IV.

H7 Administer drugs by any route (two or more nurses).

H8 Administer vasoactive or antineoplastic drugs.

Class I: Neurologic Management - Interventions to optimize neurologic function ${ }^{(11)}$.

I1 Manage signs and symptoms of hypoactivity/agitation

I2 Manage the patient's orientation patterns

I3 Evaluate the neurological reaction of the patients to verbal, tactile and painful stimuli.

I4 Monitor intracranial pressure.

Class K: Respiratory Management -Interventions to promote airway patency and gas exchange ${ }^{(11)}$.

K1 Aspirate the airways up to three times in 24 hours.

K2 Aspirate the airways more than three times in 24 hours.

K3 Provide non-invasive administration of oxygen (O2 catheter, tent, hood or mask).

K4 Control the patient's airways by non-invasive mechanical ventilation.

K5 Control the patient's airways using invasive mechanical ventilation. 
Class L: Skin/Wound Management - Interventions to maintain or restore tissue integrity ${ }^{(11)}$.

L1 Monitor and evaluate the risk of skin lesions.

L2 Perform massages.

L3 Care for wounds, surgical incisions, stoma,or needle/drain/catheter insertion sitesonce per day.

L4 Care for wounds, surgical incisions, stoma, or needle/drain/catheter insertion sites twice per day.

L5 Care for wounds, surgical incisions, stoma, or needle/drain/catheter insertion sites three times per day.

L6 Provide care for multiple wounds, eviscerations or a large wound (burns) that requires more than 40 minutes to perform at any frequency.

Class M: Thermoregulation - Interventions to maintain body temperature within a normal range ${ }^{(11)}$.

M1 Monitor body temperature up to three times per day.

M2 Monitor body temperature more than three times per day.

M3 Continuously monitor body temperature.

M4 Use and control equipment for heating and cooling body temperature.

M5 Apply cold or hot compresses.

M6 Give an immersion bath for regulating body temperature in a given shift.

Class N: Tissue Perfusion Management -Interventions to optimize blood and liquid circulation to the tissues ${ }^{(11)}$.

N1 Monitor peripheral perfusion/signs and symptoms of bleeding.

N2 Perform peripheral venipuncture to administer drugs/liquids for maintaining blood volume intravenously.

N3 Perform multiple venipunctures in 24 hours.

N4 Perform rapid administration of liquids for intravenous or intraosseous blood volume replacement.

N5 Monitor central venous pressure.

N6 Monitor mean arterial pressure.

N7 Monitor pulmonary capillary pressure.

N8 Administer blood derivatives.

N9 Care for mechanical circulatory support equipment.

N10 Insert a peripherally inserted central catheter in the last 24 hours.

Chart 3 - Validated nursing activities in Domain 3 - Behavioral - São Paulo, SP, 2010

Domain 3: BEHAVIOR - Care activities that support psychosocial functioning and facilitate lifestyle changes ${ }^{(11)}$.

Class O: Behavioral Therapy-Interventions to reinforce or promote desirable behaviors or alter undesirable behaviors ${ }^{(11)}$.

O1 Supervise social/recreation activities.

O2 Participate in social/recreation activities.

O3 Provide constant surveillance of the patient/environment.

O4 Provide care in situations where the patient is agitated and/or aggressive and withdrawn.

O5 Provide a therapeutic toy.

Class R: Coping Assistance -Interventions to assist another to build on his/her own strengths, to adapt to a change in function or to achieve a higher level of function ${ }^{(11)}$.

R1 Refer the patient/family to social/spiritual services.

R2 Support the patient/family in adapting to the disease situation.

R3 Provide clarification/guidance about the specific diagnosis/treatment/procedure.

R4 Participate in meetings with the patient/family/multidisciplinary team for information, decision-making and solutions for problems arising during their stay.

R5 Stay with the patient/family during periods of anxiety and/or times of suffering/hold a child on his or her lap.

Chart 4 - Validated nursing activities in Domain 4 - Safety - São Paulo, SP, 2010

Domain 4: SAFETY - Care that supports protection against harm ${ }^{(11)}$.

Class U: Crisis Management -Interventions to provide immediate short-term help in both psychological and physiological crises ${ }^{(11)}$.

U1 Assist urgent/emergency procedures, such as intubation, chest drainage, catheter insertion, pacemaker insertion, urgent/emergency surgery, in the last 24 hours.

U2 Assist during a seizure in the last 24 hours.

U3 Participate in cardiopulmonary resuscitation or cardioversion in the last 24 hours.

Class V: Risk Management - Interventions to initiate risk reduction activities and continue monitoring risks over time ${ }^{(11)}$.

V1 Monitor RR, HR and BPup to three times in the last 24 hours.

V2 Implement and control precautions for contact/droplets/aerosols.

V3 Monitor RR, HR and BP and oxygen saturation.

V4 Adopt measures to prevent falls/escape/suicide.

V5 Physically restrain the patient during any shift. 
Chart 5 - Validated nursing activities in Domain 6-Health System - São Paulo, SP, 2010

\begin{tabular}{|ll|}
\hline Domain 6: HEALTH SYSTEM - Care that supports effective use of the healthcare delivery system ${ }^{(11)}$. \\
\hline Class Y: Health System Mediation - Interventions to facilitate the interface between patient/family and the healthcare system $^{(11)}$. \\
\hline Y1 & Instruct the patients/caretaker about self-care activities at home. \\
Y2 & Train the patient/caretaker to perform self-care at home. \\
Y3 & Provide home visits to prepare the environment for the patient's self-care needs. \\
\hline Class a: Health System Management - Interventions to provide and enhance support services for the delivery of care ${ }^{(11)}$. \\
\hline a1 & Participate in conference and replenish controlled drugs used by the patient during any shift. \\
a2 & Solicit and evaluate new products/equipment for use by the patient. \\
a3 & Prepare and monitor a nurse practitioner or nursing student while performing specific activities with the patient during a shift. \\
a4 & Accompany the patient to other locations within the institution during a shift. \\
a5 & Prepare and accompany the patient to another institution during a shift. \\
\hline Class b: Information Management - Interventions to facilitate communication about healthcare & \\
\hline b1 & Create reports about the patient to provide notification about adverse events or to help continued treatment by other employees/services. \\
b2 & Apply and document nursing procedures. \\
b3 & Participate in a meeting with a nurse practitioner to evaluate care. \\
b4 & Create and implement research protocols involving the patients. \\
\hline
\end{tabular}

\section{DISCUSSION}

Conducting this study allowed us to reproduce and analyze the activities directly related to determining the nursing workload in pediatric wards.

The method used for the study allowed us to better approximate the reality of pediatric patient care and to understand the care and management procedures for determining nurse staffing. The interventions and the activities involved in nursing care, the patients' dependence on the nursing team and the estimated time to perform the various listed activities were analyzed and discussed.

The participation of specialty nurses with vast professional experience in care, teaching and research who were committed to building knowledge in the are as related to this instrument and recognized the importance and the need for the study and their role was essential for improving and validating the instrument because they had expertise in the right areas. They believed that the activities chosen for the instrument were relevant to pediatric nursing.

Sorting the activities according to the estimated time needed to perform them produced a set of actions that appear to impose varying workloads on the nursing team. Therefore, studies will be required to confirm the average time taken to perform each activity. From this information, the work volume demanded by pediatric patients can be calculated, and thus an adequate number of nursing employees and their qualifications for assisting this clientele can be determined.

Choosing the $\mathrm{NIC}^{(11)}$ as the standardized language system was essential for the instrument development process because it allowed the content to be categorized using appropriate nomenclature that is recognized worldwide, thus providing a common meaning nationally and internationally. Using this taxonomy ${ }^{(11)}$ also permitted the various dimensions of care, from physiological to psychosocial, to be taken into account, thereby increasing the number of activities performed by the nursing team.

However, the lack of national and international studies conducted specifically on pediatric patients prevents us from conducting a comparative analysis of the study's results.

\section{CONCLUSION}

Conducting this study allowed us to create and validate an instrument for identifying the nursing activities performed in pediatric wards. The method used was sufficient for the aims of the study and can be used as the basis for additional studies on this topic.

Identifying activities that are representative of the nursing team's workload revealed the need for further studies to test the clinical reliability and validity of the proposed instrument. Conducting these tests will demonstrate the applicability of the instrument in clinical and managerial practice and determine the time spent performing each of these activities, resulting in an instrument that measures the nursing team's workload in pediatric wards.

This study is, therefore, an opportunity to systematize the processes related to nurse staffing based on the needs of pediatric patients, filling a current gap in this area.

We believe that this study has contributed to field of research aimed at overcoming the difficulties in proposing parameters for determining nurse staffing needs in pediatric wards to provide excellent care and safety for patients in this area. 


\section{REFERENCES}

1. Gaidzinski RR. O dimensionamento de pessoal de enfermagem em instituições hospitalares [tese livre-docência]. São Paulo: Escola de Enfermagem, Universidade de São Paulo; 1998.

2. Fugulin FMT, Gaidzinski RR, Castilho V. Dimensionamento de pessoal de enfermagem em instituições de saúde. In: Kurcgant P, coordenadora. Gerenciamento em enfermagem. 2a ed. Rio de Janeiro: Guanabara Koogan; 2010. p. 121-35.

3. Fugulin FMT, Gaidzinski RR, Kurcgant P. Sistema de Classificação de Pacientes: identificação do perfil assistencial dos pacientes das unidades de internação do HU-USP. Rev Latino Am Enferm. 2005;13(1):72-8.

4. Conselho Federal de Enfermagem (COFEN). Resolução COFEN 293/2004. Fixa e Estabelece Parâmetros para o Dimensionamento do Quadro de Profissionais de Enfermagem nas Unidades Assistenciais das Instituições de Saúde e Assemelhados [Internet]. Brasília; 2004. [citado 2010 mar. 15]. Disponível em: http://novo.portalcofen.gov.br/ resoluo-cofen-2932004_4329

5. Fugulin FMT, Silva SHS, Shimizu HE, Campos FPF. Implantação do Sistema de Classificação de Pacientes na Unidade de Clinica Médica do Hospital Universitário de São Paulo. Rev Med HU-USP. 1994;4(1/2):63-8.

6. Miranda DR, Rijk A, Schaufeli W. Simplified Therapeutic Scoring System: the TISS-28 itens-results from a multicenter study. Crit Care Med. 1996;24(1):64-73.

7. Miranda DR, Nap R, Rijk A, Schufeli W, Lapichino G; TISS Working Group. Nursing activities score. Crit Care Med. 2003;31(2):374-82.

8. Georgieff MK, Mills MM, Bhatt P. Validation of two scoring systems which assess the degree of physiologic instability in critically ill newborn infants. Crit Care Med. 1989;17(1):17-21.
9. Gray JE, Richardson DK, McCormick MD, Workman-Daniels K, Goldmann DA. Neonatal therapeutic intervention scoring system: a therapy-based severity-of-illness index. Pediatrics. 1992;90(4):561-7.

10. Dini AP. Sistema de classificação de pacientes pediátricos: construção e validação de instrumento [dissertação]. Campinas: Faculdade de Ciências Médicas, Universidade Estadual de Campinas; 2007.

11. Bulechek GM, Butcher HK, Dochterman JM. Classificação das Intervenções de Enfermagem. 3ạ ed. Rio de Janeiro: Elsevier; 2010.

12. Soares AVN, Gaidzinski RR, Cirico MOV. Nursing intervention identification in rooming-in. Rev Esc Enferm USP [Internet]. 2010 [cited 2012 May 14];44(2):308-17. Available from: http://www.scielo.br/pdf/reeusp/v44n2/en_10.pdf

13. Garcia EA, Fugulin FMT. Nurses' work time distribution at Emergency Service. Rev Esc Enferm USP [Internet]. 2010 [cited 2012 May 14];44(4):1032-8. Available from: http:// www.scielo.br/pdf/reeusp/v44n4/en_25.pdf

14. Bonfim D, Gaidzinski RR, Santos FM, Gonçalves CS, Fugulin FMT. The identification of nursing interventions in Primary Health Care: a parameter for personnel staffing. Rev Esc Enferm USP [Internet]. 2012 [cited 2013 Jan 12];46(6):146170. Available from: http://www.scielo.br/pdf/reeusp/ v46n6/en_25.pdf

15. Possari JF. Dimensionamento de profissionais de enfermagem em Centro Cirúrgico Especializado em Oncologia: análise dos indicadores intervenientes [tese doutorado]. São Paulo: Escola de Enfermagem, Universidade de São Paulo; 2011.

16. LoBiondo-Wood G, Haber J. Pesquisa em enfermagem: métodos, avaliação crítica e utilização. 4a ed. Rio de Janeiro: Guanabara Koogan; 2001. 